Huuki, Tuija \& Lanas, Maija (2019). Sámi child-adult/past-present entanglements in a painful lecture at university. In (P. Rautio \& E. Stenvall Eds.). Social, Material and Political Constructs of Arctic Childhoods: An Everyday Life Perspective. Springer. 135-148. 


\title{
Sámi child-adult/past-present entanglements in a painful lecture at university
}

\author{
HOW AFFECT JUMPS ACROSS ‘TIME-PLACE-AGE’ DOMAINS
}

Singing is good. Whistling is bad. Boys are good. Boyish girls are bad. Berries are good. Swamps are bad. Swans, pied flycatchers, foxes, and squirrels are bad. Drakes, tits, lynxes, and weasels are good.

My life began in the 1970s as the child of an Inari Sámi ${ }^{1}$ mother and a Finnish father, in a small village in rural northern Finland, in the Inari Sámi homeland area. On the basis of its cultural ethos, the area could be portrayed as a melting pot of Finnish, Sámi, Norwegian, and Russian tradition in an increasingly globalizing national culture. With my Inari Sámi kin from my mother's side around me, I grew up in an environment surrounded by not only the atmosphere of a northernmost Finnish municipality, but also the traditional Inari Sámi livelihoods of reindeer herding, fishing, and gathering.

In this chapter we explore how affective energies are transmitted not only intersubjectively, but also intergenerationally and through material objects. This is done by looking at how a lecture, which turned unprecedentedly painful for the lecturer (Tuija, a Sàmi descendant woman, $1^{\text {st }}$ author) opened an unprecedented window to her childhood experiences in a rural northern Sàmi community in Finland. This chapter explores the 'transversal flashes' (Guattari 1995, 93) where affect jumps across time-space domains, created by experience in a complex network of shifting discursive-material forces that Karen Barad (2007) calls 'apparatuses'. In this apparatus, objects, animals, utterances, institutional and recreational bodies, human body parts, and atmospheres among a myriad other fragments pulse and vibrate. We analyse how these vibrations link to the lecturer's personal history coloured by gender violence as well as Sámi families' traumatic past.

Researchers have studied Sámi childhoods recently from perspectives of language (Pietikäinen and Pitkänen-Huhta 2013), future visions (Jonsson, Sarri, and Alerby 2012), identity (Ågren, 2008), education, and schooling and teaching (Hertting and Alerby 2009; Lillemyr et al. 2010; Jannok-Nutti 2013). Such research has provided important insights into the life-worlds of Sámi children in schools and beyond - and into tensions between Sámi and Western cultures. However - reflecting the nature of the larger body of modern childhood studies and of modern cultural imaginaries — such studies tend to view childhood through a binary 'childhood-adulthood' logic and developmental stages;

\footnotetext{
1 The Sámi homeland region, 'Sápmi', spans the circumpolar areas of Norway, Sweden, Finland and Kola Peninsula of Russia. There is a total population of approximately 100,000 across the four countries, of which approximately 10,000 reside in Finland. The Sámi are the only ethnic group in the European countries to be recognised as indigenous people. In Finland, Sweden and Norway a Sámi is defined as a person of Sámi origin who feels oneself to be Sámi and who either has Sámi as their first language, or had at least one parent or grandparent who had Sámi as their first language. There are ten Sámi languages in total, and three of them are spoken in the Sámi homeland area of Finland. The Sámi living in Finland can thus be divided linguistically in three groups: North Sámi, Inari Sámi and Skolt Sámi. The largest group is North Sámi (davvisámegiella), which is used in Finland, Sweden and Norway (for more information see: www.samediggi.fi). What is important is the connectedness to Sámi ancestry, the relationship to Sámi community, language and via language to Sámi culture and a feeling of being Sámi (Lehtola, 2002).The Sámi homeland area in Finland includes the municipalities of Enontekiö, Inari, Utsjoki and part of Sodankylä, covering an area of 35,000 $\mathrm{km}^{2}$. The Sámi cultures are built on the traditional livelihoods of reindeer herding, fishing and gathering over a period of thousands of years. Sámi communities have experienced a structural change via assimilation practices, and the rapid decline of the traditional Sámi livelihoods of fishing and reindeer herding to make way for industry and tourism.
} 
"development" is regard as occurring in a linear, past-present continuum, defined by boundaries of various types. Those boundaries serve mainly to distinguish childhood from not-childhood (see Alanen and Mayall 2001), categorising often based on ideas of developmental psychology.

Concurring with recent feminist new materialist and posthumanist scholarship, this chapter rejects individualist and developmentalist views of childhood as more or less fixed. Instead, we contend, one should view childhood as emergent, as open to the not-yet-known, and as constituted in affective assemblages or entanglements of other bodies, things, and matter (Lenz Taguchi, 2010; Renold and Mellor 2013; Holford, Renold \& Huuki 2013; Huuki and Renold 2016; Osgood and Scarlet 2016). We propose a notion of childhood that connects to a posthuman and new materialist scholarship critical of traditional humanism, which calls for radical post-individual, non-anthropocentric theories of subjectivity.

Posthuman scholarship challenges us to take seriously the 'more-than' approach to research, embracing the more-than-individual, more-than-human, more-than-present, and other-thanconscious nature of phenomena. 'More-than-individual' refers to how events and phenomena are constituted in complex material-discursive networks of relations (Barad, 2007; Deleuze and Guattari 1987; Alaimo and Hekman, 2008; Braidotti, 2013; Manning, 2013). 'More-than-present' means how personal experiences occurring in the present are entangled in collective histories; the concept allows for descriptions of how personal and collective past and present intertwine without resorting to psychological 'explaining' and potential pathologising (Davoine and Gaudilliere 2004; Walkerdine and Jiminez 2012; Dragojlovic 2015). 'Other-than conscious' refers, in turn, to how present experiences are entangled with histories through affective transmission in a other-than-conscious or less than conscious way (Blackman and Venn 2010; Walkerdine 2010; Blackman 2012).

This chapter focuses in particular on the 'more-than-present' and 'other-than-conscious,' in an attempt to understand how affect 'jumps' (Stewart 2007) across time-space-age domains, composing a certain type of historically emerging arctic childhood and carrying that emergent childhood across temporal domains. Feminist new materialist theories have considered affect as non-conscious, immaterial, or autonomous processes (see Massumi 2002; Blackman and Venn 2010) that circulate between bodies (Brennan, 2004; Blackman, 2012), their environments (Navaro-Yashin, 2012), and across times and places (Dragojlovic 2015). Affect has also been defined as a prepersonal intensity, that "is felt before it is thought: it has visceral impact on the body before it gives subjective or emotive meaning... Affect is...different from emotion: it is an a-subjective bodily response to an encounter. Emotion comes later; a classifying or stratifying of affect" (Hickey-Moody and Malins, 2007, 9). Events can become charged with intensities, forming affective atmospheres that one can describe as experiences occurring across human and non-human bodies, beyond the subject-object and pastpresent distinction (Dragolovic 2015, 324).

Walkerdine and Jiminez (2012) propose that affects can often transmit historical patterns of social organization silently and that affects may come to be sedimented through relations of time and space in routines, practices, ways of relating, and manners of holding and experiencing the body. Through repetition over time, such routines and practices become settled patterns. In this fashion, each community and its people produce particular forms of relating, organization, and modes of being.

Focusing on the transmission of affect allows for the invitation of new, often unconsidered questions regarding childhood, such as 'how does childhood leap though time, place, and generation; from past to present; and from a childhood school and grandmother's house to an academic lecture hall, emerging in events and situations in adulthood?' This study explores how affectivity operates through and across the binary oppositions of 'child-and-adult' and 'past-and-present.' We contend that 'here' is not the only constituent of a situation and mover of power relations in a person's life. Rather, situations are composed of myriads of material-historical-semiotic-discursive forces, in which 
assumed distinctions between girl and woman, adult and child, now and then, or personal and shared may become blurred and entangled. This study will also examine the historical constitutiveness of social relations, which is vastly under-explored in social studies.

In order to demonstrate the above, we will present an event in the 'present'; namely, a university lecture that was surprisingly painful for the lecturer, Tuija, the first author of this chapter. We will show that this event was a product of material-discursive entanglements of discourses, places, materialities, histories, and embodied practices - and that the constitution of the event occurred through affective encounters taken place in different times and places. We will then move to examine the seemingly arbitrary stories evoked by this discomforting lecture, following which we will scrutinize the historical events and planes within which those stories emerged. Our purpose is to provide an image of how affects leap, jump, and surface, and to gesture towards the limits of humanistic, individualized theorizations of childhood.

\section{THE PRESENT}

I am 45 minutes early, as I usually am when giving lectures, wanting to make sure everything is working well. I am here to deliver a talk about normalized, mundane forms of power and violence in young peer cultures. I have prepared thoroughly; the structure is well put together and I have made careful notes in advance. Although I have often lectured about this topic, and have been studying power in people's peer relations for over a decade, I never feel secure when entering a lecture hall as a lecturer. I sit behind the table at the front of the lecture hall and watch the subject teacher students start drifting in-mostly women from several different faculties. The course coordinator has told me that the students have been waiting eagerly for the lecture. Everything starts well.

As I am lecturing, I feel tension and anxiety building. I feel tension around me, in the lecture hall, in the students. The oddly hushed silence that prevailed in the room from the first minute of the lecture turns into student fidgeting. They whisper and snicker; they offer each other looks and the tone of their questions is unsettling. I feel uncomfortable, unsafe, and stuck: I do not come out from behind the booth during the lecture or deviate from my lecture notes. Aside from the fidgeting and snickering, the room is stagnant, pregnant-with what I do not know. I stand, a weight on my shoulders, while others observe me. The weight affects how I carry myself; how I, 44 years old, hide behind the podium; how I cling on to the lecture notes; how I use my voice; and how my gaze seeks contact from the back wall instead of from the listeners.

Over the eighteen months following the discomforting lecture, we spent a number of sessions discussing and disentangling the 'qualitative multiplicities' (Braidotti 2006) that rippled across the event. To unpack and understand what occurred, we engaged with the pain that the lecture caused Tuija. We began by compiling a detailed description of what occurred in the lecture and arrived at the conclusion that the discomfort of this pedagogical event was not produced solely by the sensitive and emotional topic, the pedagogy, the material surroundings, the student expectations, or the discourses of teacher education. Instead, such pain is produced when all these aspects come together as the constitutive forces of normative teacher education (Lanas and Huuki 2017).

In this chapter, we continue examining the lecture event and its inter-intra-connectedness to wider, material-discursive fields of power. Employing Karen Barad's agential realism $(2003 ; 2007)$ and a psychosocial analysis of affect (Walkerdine, Olsvold, and Rudberg, 2013; Dragojlovic 2015), we conclude that the event is connected to Sámi childhoods and to the cultural assimilation of the Sámi through intergenerational affective transmission. We map, therefore, how the painfulness of the lecture emerges through the intra-acting flows (Barad 2007) and convergence not only of physical objects - human, non-human, and other bodies - but also personal and collective traumatic events that have occurred in the past. We demonstrate through analysis how the discomfort experienced in 
the above lecture was situated in a long history of violence, trauma, and ethnic discrimination, analyzing how Tuija is connected relationally to the ghostly presence of a colonial past and that of her Sámi kin. Her experience was produced through and across binary distinctions of child-adult and past-present. Considering affectivity inter-generationally (Dragojlovic 2015), we show that affect is transmitted not only between the bodies of those Sámi who experienced violence and forced assimilation, but also through the body of their descendant Tuija and through her embodied sense of connectivity to the past.

This type of rhizomatic cartography, inspired by Deleuze and Guattari (1987), allows us to place elements of various qualities and features in the same analytical frame, so as to explore power relations and affective leaps though time, place, and age. However, this chapter does not aim to 'explain' events in relation to each other or to imagine any type of causality. Instead, we aim to understand how childhood emerges as part of broader historical flows of force; not as a distinct period in time, somehow separable from all other periods, but intertwined with multiple affective force relations.

In considering the affective charges surfacing during Tuija's lecture, we attempt to become sensitive to the indirect forms of communication discussed, focusing in particular on that which is "indirect... unthought and unprocessed and yet communicated" (Walkerdine, Olsvold and Rudberg, 2013, 276). For example, in Tuija's case, the heavy colonial past of the Sámi produced social expectations that carried connotations of femininity as legacies different from those of a Finnish context only. Affective charges of the past further place Tuija's experiences of discrimination in a historical context. This in turn allows us to glimpse those 'transversal flashes' (Guattari, 1995/2005, 93) in which affective traces of the past leap across domains of 'time-space' created by experience in a complex network of shifting discursive-material forces.

The analysis maps affects as they leap back and forth through different sedimentary historical layers: from one, the present time of the lecture, to two, Tuija's memories of local community practices from her childhood, to three, adulthood, to four, references to historical traditions and communal practices of the Sámi and her childhood community. In what follows, the text in cursive is Tuija's memories as constructed with another Sámi woman, her close relative, with whom Tuija spent a lot of time in childhood; these memories surfaced as Tuija engaged with painful affects in the lecture. The cursive text does not aim to provide a coherent 'voice.' Instead, Tuija's detailed memories are interwoven with the memories of her kin and with literature that later became a part of those memories. The noncursive text theorizes how those memories exceed time and place, personal and shared, childhood and adulthood. We engage with other affective events that surfaced as the lecture was discussed and trace the historical context in which these events occurred.

\section{SURFACING HISTORICAL LEGACIES OF INDIGENOUS AND FINNISH CHILDHOOD}

My class in school had sedimented, unequal peer group hierarchies; and power struggles became more complex the older the students became. Thriving in battles required something I felt I lacked. I had learned carefully to be 'good' and adjustable and I lacked resistance skills. I was in the margins among the girls in the class and the teacher had no interest or means to change this. I achieved highly in school nevertheless and competed in swimming at a national level. When I was eleven, the students were to give presentations on an animal. I chose a weasel. The presentation was to take five to ten minutes standing in front of the class without notes. I was asked to go first by the teacher. I failed horribly. After my presentation the rules were changed so that the others could use notes. Many years 
later I heard that the teacher had said it was a good lesson for me to be dropped from a pedestal, so I wouldn't get cocky because of success as a swimmer and a schoolgirl.

From the nineteenth century until World War II and into the 1960s, Nordic Sámi policies have been characterized by discrimination against the Sámi in various spheres of life. This took place through various ways from government action to local relations and day-to-day life among the Sámi themselves (Kvist, 1992; Lehtola, 2016; Hansen, Melhus, Høgmo, and Lund, 2008; Pikkarainen and Brodin, 2008; Bals, Turi, Skre and Kvernmo, 2010). One central arena in which a systematic repression of Sámi language and culture occurred in the post-war period - intertwined in processes of Nordic nation building - was in the education system and more specifically in boarding schools. In Finland, the new 'Public Education Act' of 1947 made it compulsory for everyone to attend school. Following this act, boarding schools were built for those children, Finnish and Sámi, who lived in remote rural communities (Rasmus, 2008). Boarding schools in Finland did not have blatant assimilation tactics written into their education policy. However, organized education played an important role in gaining control over the Sámi land and people (Bastien, Kremer, Kuokkanen and Vickers, 2003). The Finnish elementary school system, which served as an important supporting pillar in building a Finnish national identity, embraced a common practice of excluding Sámi identity.

I grew up as a second generation boarding school student, as my mother was one of many children who, at the age of seven, were taken from the center of her own home and Sámi community in Kessivuono comprising about twenty persons. She was moved to a boarding school at the edge of a foreign culture and language. She resided in a dormitory on site at the school, a full day's travel from her home, and was only allowed to go home during long holidays.

Boarding school demanded Finnishness from the Sámi children, who were forced to become 'proper' Finnish citizens in various ways, including use of a strict daily time schedule and Finnish language, food, symbols, and clothing. Punishments were dealt to those who did not conform to the new identity. Within that educational environment, abuses of power were common between Finns and Sámi but also in Sámi groups (Rasmus, 2008).

The thought of all the children being legally forced to move away from home at the age of seven was too painful for the family, who decided to move to the village in which the school was located. In this manner my mother was able to attend school from home. I sometimes heard from her siblings and from other local people of the intimidation, discrimination, and harassment that continued throughout their basic education. Something that has always amazed me is the manner in which these violent stories were told: their meaning was always downplayed or they were saturated with humor. Nevertheless, as a result, when my mother reached adulthood, she had given up almost everything referring to the Sámi: her language, her name, her clothes, and other cultural symbols. Reindeer herding and fishing were skills that stayed with her and which also I inherited.

Through assimilation politics, a first-generation boarding-school Sámi childhood was rooted in complex contradictory legacies of indigenous and cultural assimilation entangled with a history of place, resulting in the loss of cultural symbols and of the Sámi language of Sámi children - and breaking social links between the nation, people, and discrimination. This shaped everyday practices and experiences for children (Kuokkanen, 2003; Rasmus, 2008; Huuki and Juutilainen 2016).

As has been demonstrated in other cultural contexts (To, 2015), lingering experiences of the national repression of the Sámi culture and language did not remain only with the post-war generation that had direct experience of assimilation politics; those experiences continue to scar and haunt the next generation, who live their adulthood in the twenty first-century. The next section aims to demonstrate how this occurred through inter-generationally transmitted affective practices in Tuija's childhood. 
THE GOOD-AND-THE-BAD AND THE INTER-GENERATIONAL TRANSMISSION OF TRAUMA AMONG THE SÁMI

Everything is either good or bad. The divide is simple and you can immediately say which something is, but you cannot choose which it is. It just is. Singing is good. Whistling is bad. Boys are good. Boyish girls are bad. Berries are good. Swamps are bad. Swans, pied flycatchers, foxes, and squirrels are bad. Drakes, tits, lynxes, and weasels are good. My mother is good. My father is bad; he doesn't belong to the Evangelical Lutheran church. The reason for this categorization is never discussed in the family or in the local community.

We are walking in a graveyard. The land forms a steep hill. In the higher ground are the graves of devout Christians and in the lower part are the others, including soviet partisans; that way, their bodies are closer to hell. My grandmother, the matriarch, nods towards the lower part and says: 'that's where your father will go.'

My grandmother was the matriarch in the family, questioned by no one. Any dissent was forbidden and difficult topics or miscommunications were not to be mentioned. Open conflict was avoided, but subtle hints through which someone was made to feel inferior were abundant. Children were harshly forbidden from expressing negative opinions or emotions and were to be silent and obedient, particularly the girls. Emerging tension in the atmosphere was the only sign of any unsurfaced issues. You could feel the tension in your body.

The responsibility for situations is often placed on the people within those situations, on their personal incapabilities or 'pathologies,' rather than on the structural and political systems that produce the situations. Therefore - we argue - the events and phenomena in question must be located in history; in this case, in a longitudinal cultural assimilation to which the Sámi have been subject for a long time, as have many indigenous people around the globe. This type of systematic repression of culture and language, involving unequal power relations, has had a massive impact on the lives of Sámi people, causing anxiety and experiences of discrimination and trauma. The birth mechanism of trauma must be foregrounded

Drawing on the French psychoanalysts Davoine and Gaudilliere (2004), Walkerdine and her colleagues $(2013,275)$ write about 'containing the social link,' by which they refer to the processes people draw on in order to understand and share their experiences; processes that include speaking, telling stories, sharing views, and singing. Walkerdine, Osvold, and Rudberg maintain that if an experience is too painful to be transmitted across a social group or down a generation, the link binding generations together will be broken. According to Davoine and Gaudilliere, one may understand trauma as a rupture in the social link; that is, a breakage within the transmission of historically located, painful suffering across generations. Volkan $(2001,87)$ writes - and we concur - that the intergenerational transmission of trauma is linked to the past generation's inability to mourn losses of people, land, or culture; indicating a community's failure to reverse injury and humiliation inflicted by another community.

Trauma becomes transmitted from one generation to another without the next generation necessarily even knowing the cause of the anxiety. This lack of overt knowledge is because experiences are often transmitted from the previous generation affectively; that is, silently, as a bodily experience in which the body registered trauma. However, the trauma in question could not be registered on a level of conscious thought (Davoine and Gaudillière, 2004). Furthermore, Davoine and Gaudilliere (2004) argue that the affective transmission of trauma is often not caused by the traumatic event itself, but by the act of keeping it secret, creating a 'missing link.' In other words, trauma is a product of a gap in conscious knowledge about painful historical experiences that begin therefore to 'haunt descendants' (Dragojlovic 2015, 320). 
Tuija's Sámi kin history is full of such breaks in trust - missing links — in relation to enforced changes created by assimilation politics, which may have caused a sense of anxiety about the survival of the Sámi community. In such circumstances, members of that community may have been concerned primarily with keeping the community alive. Therefore, one may regard the seemingly random categorizations of the Sámi as unconscious affective practices (Walkerdine, 2010); as the Sámi trying to address their 'missing links,' holding to 'good' over ' $b a d$ ' in order to cope with the life-and-death struggle confronting them, striving to keep their community together in the face of imminent demise.

Read that way, the Sámi practice of considering singing songs safe if those songs are spiritually pure-whereas whistling, according to old local mythologies, is 'calling to the devil' or 'Staalo'begins to seem more intelligible. In the above example, the Sámi form an affective link between spiritual salvation and destruction. Similarly, poisonous mushrooms are-of course-deadly, while safe mushrooms are 'reindeer food' according to the Sámi tradition, linked to reindeer, on whom livelihoods depend. Swans, in turn, local Sámi tradition asserts, take living space from humans and from smaller and more vulnerable species. In terms of gender expectations, the heavy colonial history of Sámi communities brought social expectations, carrying connotations of narrow gender norms as legacies of the past. Non-normative gender behavior-for example, female competitiveness and assertiveness - risks rupturing the rhythm a community has followed; such behavior may disturb the rhythm it has accommodated to survive. Sámi girls and women were required therefore to observe certain sets of norms such as adaptability and working hard, norms designed to maintain conditions that on one hand were difficult, but on the other must be perpetuated in order to survive in harsh subarctic environments. Against this background, one may understand more easily that the seemingly senseless constructs are maintained by the Sámi as necessary communal - yet less than conscious practices linked to survival. Indeed, we have begun to consider this kind of categorization of qualitatively different objects and entities into 'bad' and 'good' as drawing an affective, unconscious 'protective envelope' around the group, aiming to insulate the collective from further harm through acts of denial and resistance (Walkerdine and Jiminez, 2012).

Such inter-generational dynamics can be very effective, operating psycho-socially as a type of affective, collective continuum, so that continuous series of events can blend into each other gradually and seamlessly, transforming along the way. Yet those events still manage to transmit affectively; the next generation may feel anxieties they cannot name and which in a sense they experience as their own, but which do not 'belong' to them-belonging, rather, to hurt experienced by previous generations. (Walkerdine and Jiminez 2012, 10.) In this vein, the traumatic experiences of the previous generations are transmitted to Tuija and continue to haunt her. Without being able to clearly verbalize why Tuija has a deep, yet unvocabularised fear that if she does not behave as she should, if she does not stay on the side of 'the good ones,' disaster will strike again. Although Tuija tried desperately to 'fit in' as a child, even choosing to give a presentation on the weasel at school—an unconscious choice connecting her affectively to those accepted by her local Sámi culture - too many issues seemed to be pulling her to the side of the 'bad.' She considered herself 'no good' at giving presentation, 'no good' at friendship, 'no good' for having a non-Lutheran father, and 'no good' in her ambitious femininity, feeling alone and disconnected. Although Tuija's consciousness later registered the grievous consequences of the Sámi cultural assimilation faced by her kin members, and the oddness of the Sámi categorizations, she carried the affective residues of these practices with her from childhood to adulthood, including her professional life, which we will turn to in the final section of this chapter. 


\section{UNDERSTANDING PAST-PRESENT CHILDHOOD-ADULTHOOD ENTANGLEMENTS IN A PAINFUL} LECTURE EVENT

Considering affect theories and an agential-realist account of agency (Barad 2007) in the context of the lecture described at the beginning of this chapter, we contend that when Tuija enters the lecture hall, she is not merely Tuija, an academic scholar, here and now. Rather, she carries affective residues of the past with her and can be thought as a product of various human and non-human forces from the past, present, and even future. Various intra-acting material and discursive forces-including deep-seated anxiety produced by the discrimination of the Sámi; school-based, gendered peer group hierarchies; historically created expectations of nomadic-working class femininity as nice and adaptable; and expectations of working hard in harsh subarctic conditions - were transformed into an orientation that 'sets the bar high'. It makes one act in an ambitious manner, yet simultaneously fears failure and humiliation. Unconsciously, Tuija had also selected a research topic that was sensitive in nature and resonated strongly with her historical roots.

In terms of the subject area and audience, discussing normative peer violence in schools seemed to have caused deep personal memories to resurface in the student teachers at the lecture, evoking emotions and personal or collective experiences. As we state elsewhere (Lanas and Huuki 2017), the content of the lecture was also unfacilitated by the students' existing knowledge or by dominant discourses. Instead of framing the topic in terms of 'bullying,' a canon so strong in Finland that it is a relatively familiar framework for future teachers, the lecture discussed the issue in terms of "normative cruelties" (Ringrose and Renold 2010) that are entangled often in mutual friendship and relationality. Asking students to rethink childhood asks that they also rethink adulthood in relation to childhood, challenging existing ideas of what it means to be a teacher of children. Teacher education entails normative expectations of professionalism as 'being ready,' of knowledge as answers, and of teachers as those who must have those answers. Teachers may feel they have not learned enough if they are unable to apply their 'learning' directly. The lecture therefore might have engendered a 'goose bump effect' (Probyn 2004, 29-30) by which many student teachers had strong affective reactions to the lecture content.

We propose that these multiple layers of affects began circling in the lecture hall, resonating differently in different individuals. As said before, some students began to whisper and snicker, offering each other looks: and Tuija found the tone of some of their questions unsettling. Added to the affective impact of the lecture hall - the architecture of which places the lecturer at floor level while a two-hundred seat audience seating rises diagonally about ten meters above the lecturer —an array of familiar affective charges passed through Tuija's body and lingered during and after the lecture as discomfort and confusion. To understand such dynamics, we draw on the work of Ana Dragojlovic (2015), who explores how affects are sedimented in the body. Dragojlovic asserts that bodies are containers and carriers of affects that are unconsciously incorporated; dispositions and relations are transmitted by means other than speech, such as through material objects and embodied practices of remembering, and in how people contain in their bodies the presence of the past (Dragojlovic 2015).

As a marginalized 'then-girl' and descendant of assimilated Sámi people, in the lecture 'now-Tuija' becomes connected affectively to the ghostly presence of her violent past and experiences, which relate to the history of discrimination in her childhood and before her birth. It is therefore the atmosphere of the lecture hall that resonates in her. Dragojlovic writes - and we concur-that "...atmosphere is constitutive of an affective relationality that is ghostly, disturbing, stimulating and transformative; operating though a wide spectrum of intentionality emanating from human and nonhuman bodies, social relations and various geographical locations" (Dragojlovic 2015, 325). 
During the lecture in question, Tuija's body memory (Leys, 2011) becomes activated in an atmosphere of subtle hints and emerging tension - to which Tuija has become attuned - in a university lecture hall that is not part of her past. The presence of the 'ghostly' is activated by an affective atmosphere evoking and bringing to the surface unresolved, repressed social violence that occurred in the past. The event produces in Tuija a deep, non-verbalized fear that something 'bad' will occur; that she will be undermined, belittled, and made to disappear. Her expertise, training, age, and knowledge of the substance of the lecture do not save her from this fear. It emerges within the intra-action between her; the participants; the lecture hall; a classed, gendered ethnic history; and a myriad of other elements that pulse and vibrate, surfacing as a strong affective charge during the lecture in question. In order to cope with the painful situation, Tuija builds a psychological 'second skin' from her lecture notes and from the podium behind which she remains, standing still, trying to fill any holes or gaps through which the body-self could spill out into boundless space (Walkerdine 2010).

Through the mechanisms outlined above, the past jumps into the present of the lecture and that present becomes confused. In the lecture hall, in this example, it is not only an adult academic who is giving a lecture: a child is present also, speaking 'through the mouth' of the adult, through the adult lecturer Tuija has become, speaking in the name of an entire Sámi community threatened with disappearance. The lecturer is not merely an adult with a doctorate: she is also an othered Sámi fisher child, the past in the present, her childhood in the adult. Tuija carries in her a strong presence of the past; it envelopes her agency.

In this way, affectivity is inter-generational, and gestures beyond binary logic: Instead of merely acknowledging dichotomous distinctions such as 'past-present' or 'adult-child,' we contend that it is vital to consider the events, subjectivities, and violence being produced through and across such distinctions. Understanding the relationality of mind-body, human-non-human, child-adult and conscious-unconscious in this manner, it becomes clear that agency can affect and be affected by other items and entities, human and non-human, past and present, in adulthood and in childhood. Lecture halls, swans, girlhoods, snickering bodies, weasels, silences, atmospheres, graveyards, academics, swamps, teacher education, fishing, adulthood, and the rural all come together as an affective assemblage, all playing their role in the event in question. These forces pulse and vibrate among myriads of other elements so strongly that they seem to 'leak' into the present of this lecture hall, in the form of Tuija's anxiety. Together, these forces and elements form a ferocious more-thanhuman apparatus (Barad 2007) that impairs Tuija's agency with the affective weight of the commodified, exploited history of the Sámi people. What on the surface seems to be individual painfulness in the here and now of the lecture hall is linked inextricably to wider historical and neoliberalizing force relations at work in and around the area of the Sámi homeland, as old traditions make way for new.

\section{AND THEN: ABOUT PAST-PRESENT ARCTIC CHILDHOOD}

This chapter presented a study that calls into question the popular view of experiences as emanating from individual selves - and questions the dominating contemporary psychologized discourses of children and youth - for overlooking the historical and societal dimensions connected to emerging childhoods. With a lack of historicized analysis, painful moments tend to become individualized and located in specific children or youth, who are often seen as deficient and expected to overcome the difficult experiences within themselves. Traumas become something to overcome, not something to study and understand as interwoven in collective pasts. 
Through a posthuman material-discursive lens, we can see how this discomforting lecture is not a consequence of 'pedagogical failure' or 'individual lack,' located merely in the present or human. Nor is the lecture to be located between the discourses - that is, contemporary teacher education discourse on the knowledgeable teacher - and Tuija, the failing subject. Instead, the pain comes to matter through a long history of material-discursive intra-actions of multiple dynamic forces. Tuija's discomfort emerges in a gendered, racialized and classed assemblage entangled with space, time and matter through which anxiousness is formed. In this chapter we have attempted to make visible how elements such as history, time, place, and material objects work together and become constitutive forces, without any one element being primary.

The analysis in this chapter strives to bring into existence the sedimented layers of non-existence wiped out by powerful forces that occurred in the history of the Sámi, whose identities, cultures, land, and prestige were torn away by cultural assimilation politics in the post-war period in Finland and in other countries spanning across Sámiland. We have paid special attention to mechanisms through which affectivity operates across the binary oppositions of past-present and adult-child. Our analysis allows one to see a child as emerging within intersections of past events in which he or she was not present, and an adult as emerging at an intersection of past events in which that adult is not placed.

This important realization offers insight into how affect was transmitted between first generation Sámi, who experienced racially-based discrimination themselves, and second generation Sámi, their descendants. We have mapped how those affects travel to different times and locations, in this case a lecture hall, connecting to other bodies, human and non-human; how those affects circulate in the lecture hall; and, as connected to multiple other temporal-material-discursive forces, how those affects produce a suppressing affective machine that violates participants by causing them anxiety and repressing their agencies.

\section{References:}

Alaimo, S., and Hekman, S., (Eds.) (2008). Material feminisms. Bloomington: Indiana University Press.

Alanen, L. and Mayall, B. (2001, eds.). Conceptualizing Child-Adult Relations. Routledge, London. Barad K 2003. Posthumanist Performativity: Toward an Understanding of How Matter Comes to Matter. Signs: Journal of Women in Culture and Society 28:3, 801-831.

Barad, K. 2007. Meeting the Universe Halfway: Quantum Physics and the Entanglement of Matter and Meaning. Durham: Duke University Press.

Blackman, L. and Venn, C. (2010) Affect. Body \& Society 16 (1): 7-28.

Braidotti, R. (2006). Transpositions: Nomadic ethics. Cambridge: Polity Press.

Braidotti, R., (2013). The posthuman. Cambridge: Polity Press.

Brennan, T. (2004) The Transmission of Affect. Ithaca, NY and London: Cornell University Press.

Coleman, R., and Ringrose, J., Eds. (2013). Deleuze and research methodologies. Edinburgh: Edinburgh University Press.

Davoine, F. and Gaudillière, J.-M. (2004) History Beyond Trauma. New York: Other Press.

Deleuze, G., and Guattari, F., (1987). A Thousand Plateaus: Capitalism and schizophrenia. Minneapolis: University of Minnesota Press.

Dragojlovic Ana 2015. Affective geographies: Intergenerational hauntings, bodily affectivity and multiracial subjectivities. Subjectivity (2015) 8, 315-334.

Guattari, F. 1995/2005. Chaosmosis: An Ethico-aesthetic Paradigm. Sydney: Power Publications. 
Hansen, KL., Melhus, M., Høgmo, A. and Lund, E., (2008). Ethnic discrimination and bullying in the Sámi and non-Sámi populations in Norway: The SAMINOR study. The International Journal of Circumpolar Health, 67, (1), 97-113.

Hertting, K., \& Alerby, E. (2009). Learning without boundaries - to voice Indigenous children's experiences of learning places. International Journal of Learning, 16, 633-647.

Hickey-Moody, A., and P. Malins, eds. 2007. Deleuzian Encounters: Studies in Contemporary Social Issues. New York: Palgrave Macmillan.

Holford, N., Renold, E. and Huuki, T. 2013 What (else) can a kiss do?: Theorizing the power plays in young children's sexual cultures. Sexualities 6(5-6) 710-729.

Huuki, T. \& Renold, E. (2016) Crush: mapping historical, material and affective force relations in young children's heterosexual playground play. Discourse: Studies in the Cultural Politics of Education, 37(5), $754-769$.

Huuki, T. \& Juutilainen, S. A. (2016) Mapping historical material and affective, entanglements in Sámi woman's discriminatory experiences in and beyond Finnish boarding school. Education in the North 23(2), 3-23.

Jannok Nutti, Y 2013. Sámi Teachers' Experiences of Indigenous School Transformation: Culturally based preschool and school mathematics lessons. AlterNative: An International Journal of Indigenous Peoples. 9 issue: 1, 16-29.

Jonsson Gunnar, Sarri, Carina and Alerby Eva 2012. "Too hot for the reindeer" - voicing Sámi children's visions of the future. International Research in Geographical and Environmental Education Vol. 21, No. 2, May 2012, 95-107.

Kuokkanen, R., (2003). 'Survivance' in Sami and First Nations boarding school narratives: Reading novels by Kerttu Vuolab and Shirely Sterling. American Indian Quarterly, 27, (3-4), 697-726.

Kvist, R., (1992). "Swedish Saami policy, 1550-1990." In: Kvist, R., ed. Readings in Saami History, Culture, and Language III. Umeå: Center for Arctic Cultural Research, pp. 63-77.

Lanas, M. \& Huuki, T. (2017) Thinking beyond student resistance: a difficult assemblage in teacher education, European Journal of Teacher Education, 40:4, 436-446

Lehtola, V-P., (2016). Sámi Histories, Colonialism, and Finland. Arctic Anthropology, 52,(2), pp. $22-$ 36.

Lenz Taguchi, H. (2010). Going beyond the theory/practice divide in early childhood education: Introducing an intra-active pedagogy. London: Routledge.

Leys, R. (2011) The turn to affect: A critique. Critical Inquiry 37(3): 434-472.

Lillemyr Ole Fredrik, Søbstad Frode, Marder Kurt \& Flowerday Terri (2010). Indigenous and nonIndigenous primary school students' attitudes on play, humour, learning and self-concept: a comparative perspective, European Early Childhood Education Research Journal, 18:2, 243-267

Massumi, B. (2002) Parables for the Virtual: Movement, Affect, Sensation. Durham, NC: Duke University Press.

Manning, E. (2013). Always more than one: Individuation's dance. Durham: London Duke University Press.

Navaro-Yashin, Y. (2012) The Make-Believe Space: Affective Geography in a Postwar Polity. Durham, NC: Duke University Press.

Osgood, J. \& Scarlet, R.R. (2016). Putting post-humanist theory to work to reimagine gender in early childhood: when theory becomes method becomes art. Global Studies of Childhood. 5 (3) 346-60.

Pietikäinen Sari and Pitkänen-Huhta Anne 2013. Multimodal Literacy Practices in the Indigenous Sámi Classroom: Children Navigating in a Complex Multilingual Setting. Journal of Language, Identity, and Education, 12: 230-247.

Pikkarainen H., and Brodin B., (2008). The rights of the Sámi from a discrimination perspective. Ombudsmannen mot etnisk diskrimering (DO). DO report no 2008.1 eng.

Probyn, E. 2004. "Teaching bodies: Affects in the classroom.” Body \& Society 10 (4): 21-43. 
Rasmus, M., (2008). Baggu vuolggit, baggu birget. Samemanaid ceavzinstrategiijat Suoma albmotskuvllaasodagian 1950-1960 - logus. Publications of Giellagas Institute NR 10. Vaajakoski, Finland: Gummerus Kirjapaino Oy.

Renold, E. \& Mellor, D. (2013). 'Deleuze and Guattari in the Nursery: towards an ethnographic, multi-sensory mapping of gendered bodies and becomings', in R. Coleman \& J. Ringrose (Eds). Deleuze and Research Methodologies. Edinburgh University Press: Edinburgh, Chapter 1, 23-41.

Ringrose, J. \& Renold, E. (2010). Normative cruelties and gender deviants: The performative effects of bully discourses for girls and boys in school. British Educa-tional Research Journal, 36(4), 573596.

To, N. 2015. Haunting memories of war in Chinese cinema and diaspora: Visions of national trauma, power and autoethnographic collage. Subjectivity 8, 4, 335-357.

Volkan, V.D. (2001) Transgenerational transmissions and chosen traumas: An aspect. Group analysis 34(1): 79-97.

Walkerdine, V., (2010). Communal Beingness and affect: An exploration of trauma in an exindustrial community. Body \& Society, 16, (1), 91-116.

Walkerdine, V., and Jiminez, L., (2012). Gender, work and community after de-industrialisation. A psychosocial approach to affect. Basingstoke: Palgrave Macmillan.

Walkerdine, V., Olsvold, A., and Rudberg, M., (2013). Researching embodiment and intergenerational trauma using the work of Davoine and Gaudilliere: History walked in the door. Subjectivity, 6,(3), 272-297.

Ågren, C. (2008). Är jag en riktig same? En etnologisk studie av unga samers identitetsarbete. [Am I a genuine Sámi? An ethnological study of identity-work by young Sámi]. Doctoral Thesis inethnology, Umeå University, Umeå, Sweden. 